\title{
O letramento como estratégia de produção textual acadêmica: o projeto comunica Erechim
}

Vanessa Luisa Freiberger

Universidade Federal da Fronteira Sul

vanessa luisa25@hotmail.com

Yan Cleiton Bergozza

Universidade Federal da Fronteira Sul

yanbergozza@hotmail.com

Ani Carla Marchesan

Universidade Federal da Fronteira Sul

animarchesan@uffs.edu.br

Pedro Paulo Venzon Filho

Instituto Federal de Santa Catarina

pedro.venzon@hotmail.com

Atilio Butturi Junior

Universidade Federal da Fronteira Sul

atilio@uffs.edu.br
Andrei Pedro Vanin

Universidade Federal da Fronteira Sul

andreivanin@yahoo.com.br

Darline Balen

Universidade Federal da Fronteira Sul

darlinebalen1@gmail.com

Everton Trentin Zoraski

Universidade Federal da Fronteira Sul evertonzoraski@yahoo.com.br

Jéssica Amroginski

Universidade Federal da Fronteira Sul eamroginski@yahoo.com.br

\section{Resumo}

Este artigo objetiva apresentar e descrever as ações do projeto de extensão Comunica Erechim, desenvolvido na Universidade Federal da Fronteira Sul (UFFS), campus Erechim, desde março de 2011. O projeto parte das concepções de letramento como processo de valoração e do uso social da linguagem, constitutivo das práticas sociais e das subjetividades. Os resultados obtidos até agora demonstram a importância desse projeto, que busca oferecer aos estudantes de graduação o desenvolvimento de habilidades e competências relativas à produção textual. Ademais, é um espaço para registrar a vida institucional da UFFS e expô-la à comunidade externa, estreitando as barreiras entre universidade e comunidade.

Palavras-chave: Produção textual. Comunicação. Letramento.

\section{The literacy as a strategy of writing academic: the comunica Erechim's project}

\section{Abstract}

This paper aims at presenting and describing the actions of Comunica Erechim's extension project, developed at Universidade Federal da Fronteira Sul (UFFS), Campus Erechim, since March 2011. The project starts from conceptions of literacy as a process of valuation and the social use of language, constitutive of social practices and subjectivities. The results obtained so far demonstrate the importance of this project that 
seeks to provide graduate students to develop skills and competencies relating to textual production. Moreover, it is a space to record the institutional UFFS life and expose it to the outside community, narrowing the barriers between university and community.

Keywords: Text production. Communication. Literacy.

\section{INTRODUÇÃO}

A extensão universitária constitui um dos três eixos exigidos pelo Artigo 207 da Constituição Brasileira, no qual é afirmado que "As universidades gozam de autonomia didático-científica, administrativa e de gestão financeira e patrimonial, e obedecerão ao princípio de indissociabilidade entre ensino, pesquisa e extensão". Para atender a essa exigência, a Universidade Federal da Fronteira Sul (doravante UFFS) despende atenção especial à extensão, em seus cinco campi ${ }^{1}$, já que valoriza o espaço extracurricular do aluno, aprofunda e diversifica os seus conhecimentos e estreita as barreiras entre a universidade e a comunidade.

Dada a importância dos projetos de extensão, este artigo objetiva apresentar e descrever as ações do projeto de extensão Comunica Erechim: laboratório de produção textual, que é um projeto integrante do programa de extensão Comunica ${ }^{2}$.

Esse programa, formado por projetos desenvolvidos em quatro campi da UFFS (Erechim-RS, Chapecó-SC, Laranjeiras do Sul-PR e Realeza-PR), é um laboratório de produção textual organizado e orientado por professores da área de Letras. Como toda atividade de extensão, o Comunica também busca fazer uma ponte entre a universidade e a comunidade, através do registro e divulgação de textos jornalísticos sobre a vida universitária. Assim, o programa contribui, de um lado, para aprimorar a competência de produção textual e expandir a condição letrada dos acadêmicos (sujeitos letrados) envolvidos no projeto e, de outro, para o registro da vida institucional da UFFS. Ademais, apresenta à comunidade externa os principais estudos e atividades que estão ocorrendo ou ocorrerão na universidade, como uma forma de integrar e trazer para a universidade essa comunidade.

O projeto Comunica Erechim, que é alvo deste artigo, pretende, da mesma forma, noticiar, informar, repensar e discutir os problemas e as soluções do campus Erechim com a comunidade externa. Para apresentá-lo, dividiu-se este artigo em cinco partes: a primeira descreve a importância dos projetos de extensão; a segunda e a terceira tratam respectivamente do letramento e do papel da reescrita; a quarta parte apresenta as ações do Comunica Erechim e a metodologia de trabalho do projeto; por fim, são feitas algumas considerações finais e perspectivas em torno desse projeto.

\section{PROJETOS DE EXTENSÃO}

Segundo Souza (2000, p. 98), “a Extensão Universitária é o processo educativo, cultural e científico que articula o Ensino e a Pesquisa de forma indissociável e viabiliza a relação transformadora entre universidade e sociedade". São considerados projetos de extensão aqueles trabalhos que interagem com a comunidade, disponibilizando saberes, conhecimentos e assistência adquiridos e desenvolvidos na universidade. Em contrapartida, a universidade recebe dessa comunidade avaliações, demandas, anseios, informações etc., que alimentam novos estudos (documento do Renex, 2012).

1 Erechim e Cerro Largo, no RS, Laranjeiras do Sul e Realeza, no PR, e Chapecó, em SC.

2 Conjunto articulado de projetos e outras ações de extensão. 
Nessa concepção acadêmica ${ }^{3}$, a extensão universitária é vista como um dos pilares da universidade, já que possibilita democratizar o acesso aos conhecimentos produzidos nela. Com isso, ocorre a aproximação da sociedade com a universidade e faz com que o conhecimento que é adquirido diariamente ultrapasse as salas de aula.

A UFFS se insere nessa perspectiva de extensão universitária "como prática acadêmica que interliga a Universidade, nas suas atividades de Ensino e de Pesquisa, com as demandas da região da Fronteira Sul" (TREVISOL; CORDEIRO; HASS, 2011, p. 62).

No livro Construindo agendas e definindo rumos, em que há o relato dos fóruns temáticos ocorridos em 2010, durante a I Conferência de Ensino, Pesquisa e Extensão (I COEPE) da UFFS, formam elencados os objetivos dos projetos de extensão:

a) Garantir a Extensão Universitária como um processo educativo, cultural e científico que, articulado ao Ensino e à Pesquisa de forma indissociável, visa promover uma relação transformadora entre a Universidade e a Sociedade;

b) Estimular o diálogo de saberes entre a Universidade e a Sociedade visando à democratização do conhecimento acadêmico e à participação efetiva da comunidade na construção da Universidade;

c) Desenvolver Programas e Projetos voltados para toda a sociedade [...];

d) Difundir resultados e benefícios oriundos da criação cultual e artística e da Pesquisa científica e tecnológica;

e) Manter a Universidade aberta à participação da população [...];

f) Proporcionar ambiência acadêmica que favoreça, a partir da Extensão, a construção do conhecimento emancipatório, a capacitação para a atuação profissional do acadêmico e a sua formação cidadã;

g) Promover o respeito à pluralidade de pensamento e à diversidade cultural [...];

h) Fomentar o desenvolvimento de programas e projetos a partir de métodos participativos e da pesquisa-ação [...]. (TREVISOL; CORDEIRO; HASS, 2011, p. 62).

A partir da COEPE e dos editais de extensão, a UFFS, através da Pró-Reitoria de Extensão e Cultura (PROEC), aprovou vários projetos de extensão. Em 2012, 99 projetos de extensão e 10 programas de extensão foram aprovados nos campi da UFFS. A duração das atividades é de um ano, e cada projeto possui um determinado número de bolsas que são ofertadas aos acadêmicos.

No campus de Erechim, um dos projetos é o Comunica Erechim: laboratório de produção textual, que faz parte do programa Comunica, que pretende atender a uma das linhas prioritárias de extensão definidas durante a I COEPE: formação de leitura e de produção escrita dos alunos da UFFS.

O programa Comunica e o projeto Comunica Erechim foram coordenados, em 2012, pela Profa. Dra. Ani Carla Marchesan e vice-coordenados pelo Prof. Dr. Atílio Butturi Junior, ambos do campus Erechim. São atividades que possibilitam divulgar a vida institucional da UFFS, registrando, através de textos de esfera jornalística, tudo que acontece no campus. Dessa forma, o Comunica Erechim viabiliza o contato da universidade com a comunidade externa, encaixando-se perfeitamente nos objetivos principais dos projetos de extensão.

3 Estamos cientes da discussão acerca da existência de três concepções de extensão universitária: a assistencialista, a acadêmica e a mercantilista. O trabalho apresentado aqui se encaixa na concepção acadêmica. 
Como projetos de extensão vinculados ao programa Comunica têm-se ainda: Comunica na escola: laboratório de produção textual, projeto realizado no campus de Chapecó e coordenado pela professora Angela Derlise Stübe; Comunica Realeza: laboratório de produção textual, desenvolvido em Realeza e coordenado pelo professor Clóvis Alencar Butzge; e Comunica Cerro Largo: laboratório de produção textual, realizado em Cerro Largo e coordenado pela Profa. Dra. Cristiane Host. Todos os projetos têm a colaboração de bolsistas e voluntários dos mais diversos cursos.

Esses projetos são muito importantes para os acadêmicos e para a comunidade envolvida, pois ambos ganham com a troca de conhecimentos que tais projetos proporcionam.

\section{LETRAMENTO E A PRODUÇÃO TEXTUAL NO ENSINO SUPERIOR}

Nesta seção, num primeiro momento, serão abordadas algumas concepções de letramento, bem como seu uso no Brasil. Num segundo momento, apoiando-se sobretudo em Barton (1994a, 1994b) e Street (2003), pretende-se mostrar qual é a concepção de letramento utilizada neste projeto. Por fim, delineia-se o papel da escrita na formação do aluno no ensino superior.

No Brasil, o termo letramento chegou nos anos 90 e ganhou destaque com o trabalho pioneiro de Magda Soares e Angela Kleiman, estudiosas que versavam sobre o letramento. Categorizadas de formas distintas (TINOCO, 2008), à primeira coube um papel de introdutora, enquanto à segunda, a reputação de trazer à tona o modelo dito ideológico de letramento.

Seguindo os passos das autoras, os estudos brasileiros sobre o letramento permanecem utilizando a alcunha ideológico ${ }^{4}$, forjada em 1983 por Brian Street (1984), para dar conta de questões que ultrapassam tanto o limite tecnológico e maquínico das teorias de alfabetização quanto a redução de grupos homogêneos os quais se deveria "letrar", partindo de pesquisas etnográficas cujos resultados têm mostrado a dificuldade de reduzir os sujeitos e seus grupos ao modelo oferecido pelo cientista.

Além de Street, Barton também surge com destaque no discurso nacional sobre o letramento: por um lado, porque evoca diretamente Paulo Freire como um precursor dos letramentos ideológicos; por outro, porque oferece uma metáfora interessante para se refletir acerca do acesso ao mundo da escrita, qual seja, a ecologia: as ações com a linguagem escrita estão incluídas num meio ambiente específico, agindo, portanto, sobre ele e o influenciando, no mesmo movimento em que são influenciadas e circunscritas pela rede em que se dão (BARTON, 1994a).

Nesse caso, Barton (1994b) apontará o imperativo de se pensar ações com linguagem escrita de maneira situada, e cada evento de letramento estará ancorado numa prática social de letramento que extrapola os limites imediatos e está inscrita numa materialidade social e histórica.

Em Street (2003) e Barton (1994a, 1994b), ainda é notória a preocupação em não reduzir o letramento às práticas escolarizadas ou formais. O que esses autores chamam de "evento de letramento" ocorreria em práticas diversas em que houvesse mediação por textos escritos.

Nessa concepção, o termo letramento vai além da escrita. No ensino superior, o sujeito letrado e

$4 \quad$ O modelo ideológico afirma que as "práticas de letramento, no plural, são social e culturalmente determinadas, e, como tal, os significados específicos que a escrita assume para um grupo social dependem dos contextos e instituições em que ela foi adquirida" (KLEIMAN, 1995, p. 21). 
alfabetizado depara-se com diferentes agências de letramento (KLEIMAN, 1995), vistas como práticas sociais: a sala de aula, os colegas de classe, os laboratórios etc. Além destas, a participação em projetos de extensão constitui-se como uma importante agência de letramento. Consoante ao exposto, é através de gêneros discursivos e da interação entre si e o meio que os universitários, sujeitos letrados, têm a possibilidade de aprimorar e expandir, de maneira crítica, sua condição letrada 5 .

Partindo, pois, do letramento como entendimento da valoração e como uso social da linguagem, Kleiman aponta que "Todas as práticas de letramento destacam aspectos das estruturas de poder de uma sociedade.” (KLEIMAN, 1995, p. 38). Refletindo, ainda, acerca dos limites da educação formal - tanto na escola quanto na universidade - o Comunica pretende, da perspectiva de um laboratório de textos, ampliar o acesso à cultura escrita e fomentar uma transformação positiva na textualização dos acadêmicos.

Os alunos envolvidos no projeto Comunica participam de vários eventos de letramento, formulados nos mais variados gêneros do discurso e que têm efeitos sobre a sua produção escrita: elaboração de textos; elaboração e realização de entrevistas; participação em palestras, debates, conversas; interação com acadêmicos de outros cursos. Depois disso, selecionam as informações mais importantes/relevantes a serem divulgadas no blog (modalização do discurso, responsabilidade pela autoria dos textos). Essas práticas sociais demonstram a importância, por um lado, do projeto como fomentador da prática de letramento e, por outro, de sua relevância na formação de acadêmicos críticos e que interagem com o meio ${ }^{6 .}$

\section{COMUNICA ERECHIM}

Independente da área de formação do sujeito, uma das exigências da contemporaneidade é o desenvolvimento de habilidades e competências relativas à produção textual. Faz-se necessário, portanto, para além da formação técnica em uma área do conhecimento específica, que haja programas de extensão que se configurem em espaço de promoção de um sujeito crítico capaz de fazer a mediação entre o conhecimento acadêmico e a comunidade, resolver situações-problema, compreender o seu entorno e fazer a leitura de sua realidade social.

Com esse intuito, foi criado o projeto Comunica Erechim, que se configura em um laboratório de produção textual, cujo público primeiro é composto por estudantes de cursos de graduação da UFFS, do campus Erechim, que demonstrem interesse em participar do projeto.

A produção de textos resultante do projeto é publicada em dois blogs: no blog do programa Comunica (http://comunicauffs.blogspot.com) e no blog do projeto Comunica Erechim (http://comunicaerechim.blgspot.com). No blog do programa, que é multicampi, são postados todos os textos dos alunos participantes dos projetos de todos os campi. No blog do Comunica Erechim, por sua vez, são postados os textos dos participantes do projeto Comunica Erechim. Essa separação em blogs é importante porque, tendo um blog só do projeto Comunica Erechim, tem-se a possibilidade de os alunos mexerem no $b l o g$, alterarem a formação dos textos, do layout etc., o que não seria possível no blog do programa.

A importância desse projeto pode ser confirmada por cinco argumentos. Primeiro, porque contribui para o registro da vida institucional da UFFS, já que os textos produzidos visam reportar fatos, eventos, opiniões do cotidiano da universidade e, também,

5 O ensino superior é constituído por várias práticas sociais das quais o sujeito letrado faz parte.

6 Como delineado acima, apenas saber ler e escrever não basta para uma formação consistente. Os cidadãos, além de saberem ler e escrever, devem conseguir fazer uma leitura das diversas "agências de letramento" que surgem a ele. 
sua relação com a comunidade regional. Segundo, porque contribui para apresentar à comunidade externa os principais estudos e atividades que estão ocorrendo ou ocorrerão na universidade, como uma forma de integrá-la e trazê-la à universidade. Terceiro, porque proporciona o desenvolvimento das competências comunicativas dos integrantes do projeto por meio de situações reais de uso da linguagem, permitindo a superação da artificialidade presente em várias práticas pedagógicas. Quarto, porque possibilita que os estudantes se sintam reconhecidos pelos textos publicados nos veículos da universidade ou nos veículos externos e motivados a migrarem para textos mais complexos. E, por fim, porque possibilita tornar o dia a dia da UFFS um objeto de observação e atualização, permitindo aos estudantes melhor conhecerem e tornarem conhecidos os agentes do ensino, da pesquisa, da extensão e da administração, os seus métodos, técnicas, limites, possibilidades e motivações.

\subsection{Metodologia de execução das atividades}

O projeto Comunica prevê encontros semanais, com orientação de grupos de estudantes, com o compromisso expresso de produzir textos, inicialmente, jornalísticos, que tenham como público preferencial os professores, técnicos e estudantes da UFFS e a comunidade regional erechinense. Nesses encontros, também é definida a temática dos textos que serão produzidos por cada integrante do grupo. Cada estudante é responsável pela apresentação de pelo menos um texto de qualidade publicável, nos blogs do projeto e do programa, num determinado dia da semana, impreterivelmente. Abaixo, tem-se uma foto do layout dos blogs produzidos e alimentados pelos integrantes do projeto.
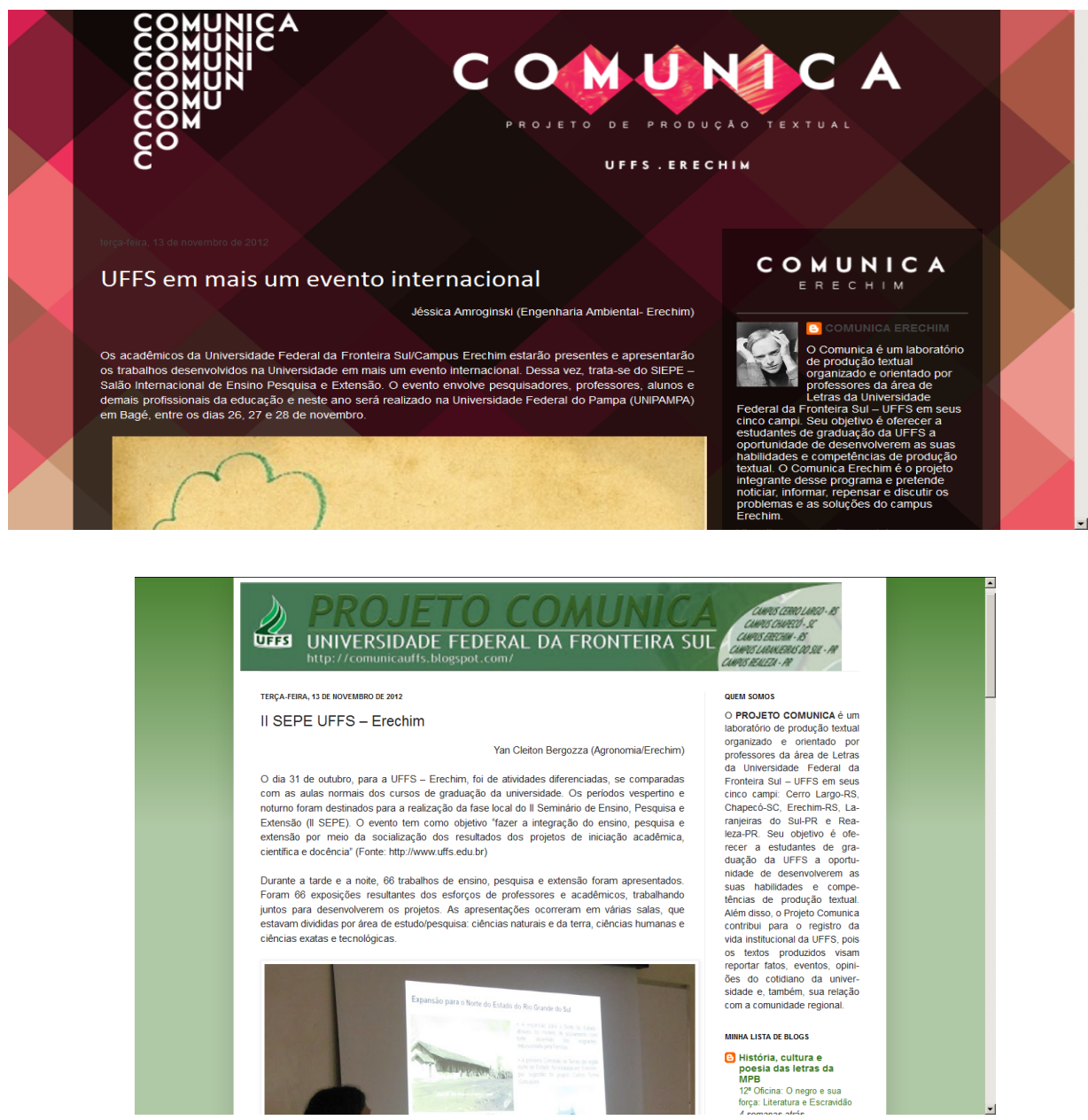

Figura 2: Blog do programa Comunica

A partir da reunião, cada estudante tem uma semana para produzir o seu texto. Nesse período, os 
textos são lidos e avaliados pelo professor-orientador, que dá a conhecer os seus comentários ao estudante, que deverá editá-lo ou reescrevê-lo para a entrega final e postagem nos referidos blogs.

Os textos publicados têm sua autoria identificada, assim, o aluno tem autonomia e decisão, se tornando um cidadão crítico que lê o seu mundo (FREIRE, 1989). Cada aluno é responsável por responder às perguntas e críticas postadas nos seus textos do blog pelas comunidades interna e externa, fazendo com que o blog, além de ser um meio de divulgação de informações, se torne um espaço de debate. Além de produzir o texto semanal, a equipe do projeto participa de atividades formativas, tais como: leituras orientadas, ciclo de debates e oficinas de produção textual.

Por fim, trimestralmente, é produzido um jornal-mural contendo os trabalhos mais relevantes do programa, a ser exposto nos murais do campus. Abaixo, tem-se uma parte do jornal-mural montado no hall da UFFS no mês de abril de 2012.
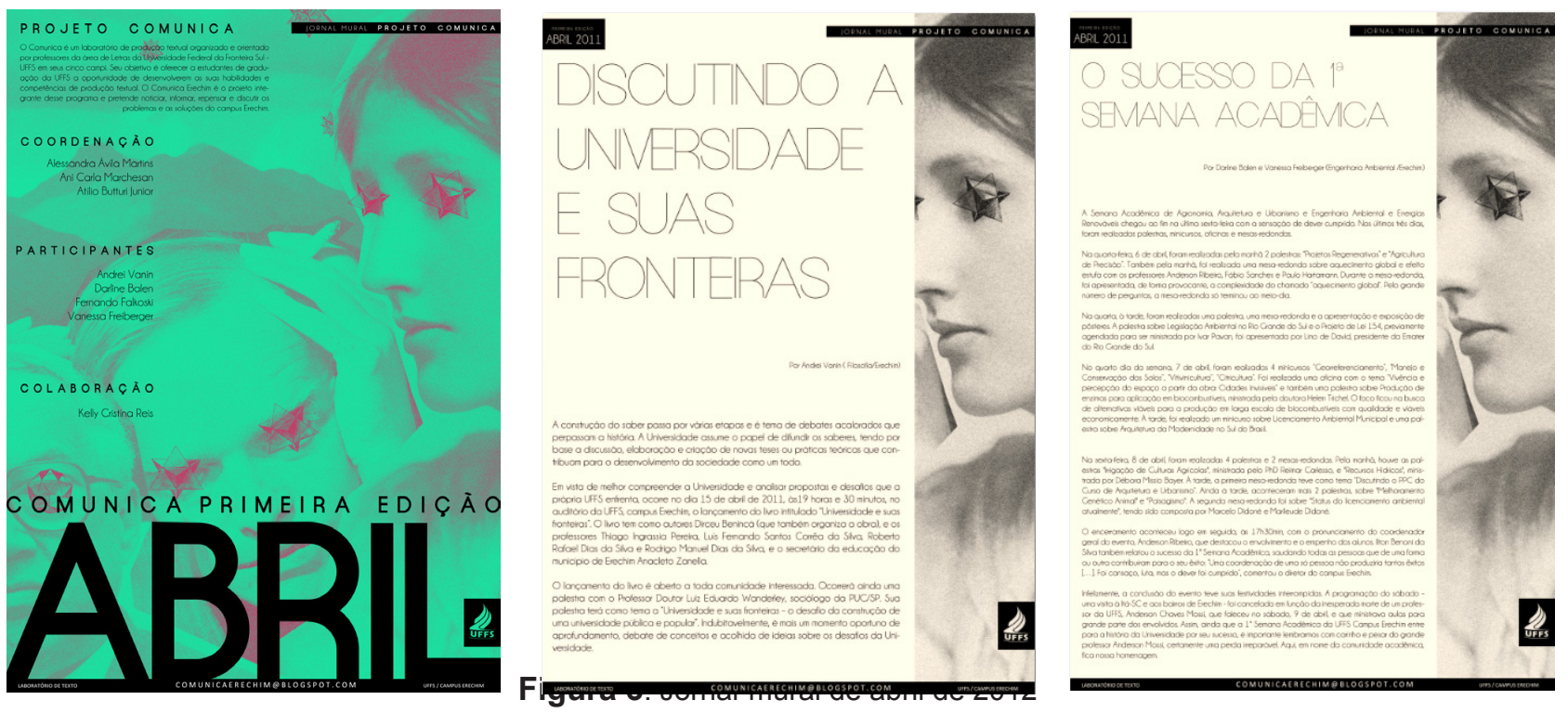

Esse projeto de extensão, que se insere na área temática da Comunicação, além de beneficiar os alunos participantes, beneficia toda a comunidade, pois demonstra um comprometimento da comunidade acadêmica em democratizar as informação da academia também para a sociedade. Assim, o projeto incentiva a prática acadêmica e o desenvolvimento da consciência social e política, visto que os alunos bolsistas são responsáveis pelos seus próprios textos, saindo do plano do relato para o plano da opinião. $\mathrm{O}$ meio de divulgação dos textos, o blog, possibilita o acesso de todos, bem como a inserção de opiniões, discussões e avaliações dos textos publicados de forma contínua.

\subsection{0 papel da reescrita}

Tratando-se de produção textual, de acordo com Koch e Elias (2009, p. 34), “[...] o produtor, de forma não linear, 'pensa' no que vai escrever e em seu leitor, depois escreve, lê o que escreveu, revê ou reescreve o que julgar necessário em um movimento constante e on-line guiado pelo princípio interacional”.

Depois desse processo, o texto é enviado ao professor-orientador, que lê o texto e apresenta sugestões que busquem guiar a elaboração dos textos dos alunos antes de publicá-lo nos blogs. Esse processo de escrita, revisão e reescrita traz benefícios para a produção textual do acadêmico, como pode-se perceber pela redução de inserções e comentários aos textos, à medida que o projeto avança.

Teberosky (2000, p. 23) afirma que a intervenção/correção interativa 'não é só um 
meio, mas assume a qualidade de um objeto, quando os usuários não só interpretam ou repetem a mensagem, mas também a produzem ou a contemplam; então o ato de escrever assume novas funções'. A autora afirma que 'escrever e escrita melhoram, e o produtor da escrita se vê afetado por seus próprios produtos $\bigotimes$ (2000, p. 23). Teberosky ainda sustenta que a materialização da mensagem escrita permite ao estudante ou a qualquer pessoa que escreve objetivar melhor seu pensamento, uma vez que se cria uma distância entre produtor/produto de sua atividade [...]. Assim, devido à permanência temporal da escrita, pode-se voltar ao texto para retocá-lo e 'transformá-lo seja no léxico, no conteúdo e na organização da mensagem ou na correção da forma' (TEBEROSKY, 2000, p. 23 apud GONÇALVES, 2012, p. 16).

Portanto, a reescrita é uma das atividades empregadas no processo de produção textual, sendo esta fundamental para o desenvolvimento das funções cognitivas relativas à escrita. Por isso, a metodologia de correção dos textos, utilizada pelos orientadores do projeto Comunica, estimula os estudantes a analisarem o que escreveram e, posteriormente, a reescreverem o texto buscando maior qualidade na produção textual.

\subsection{0 impacto do Comunica na sociedade}

Durante a execução do projeto Comunica Erechim (2012), os textos produzidos e postados pelos alunos receberam cerca de 30 visualizações diárias e mais de 900 visualizações mensais da página do blog Comunica Erechim; e cerca de 60 visualizações diárias e mais de 1.700 visualizações mensais do blog do programa Comunica (multicampi).

Esse fluxo de visualizações do blog comprova que o objetivo de divulgação institucional está sendo alcançado. Esse montante crescente de visualizações dos textos também comprova, de forma indireta, a qualidade dos textos produzidos pelos alunos, que vai ao encontro de outro objetivo do projeto: desenvolvimento das habilidades e competências de produção textual do aluno-bolsista.

\section{CONSIDERAÇÕES FINAIS}

Por enquanto, pôde-se perceber que o projeto Comunica busca produzir conhecimentos e discursivisá-los, por meio dos textos jornalísticos, à própria universidade e à comunidade externa. Por meio desse projeto, ocorrem a difusão, a socialização e a democratização dos conhecimentos existentes, bem como a divulgação de eventos e fatos importantes para a universidade. É também através de um projeto de extensão que se consegue trazer a comunidade externa para a universidade, completando a formação dos universitários que deve ser composta pelos três eixos: ensino, pesquisa e extensão, ou seja, é uma forma de socializar o conhecimento não deixando que tal conhecimento fique restrito aos alunos que passaram no processo seletivo de ingresso ao ensino superior.

Ademais, a prática do texto escrito é um processo que se tem mostrado profícuo, pois percebe-se não apenas a apropriação progressiva das competências de leitura e escrita, mas ainda o surgimento da autoria e de mecanismos políticos e subjetivos caros ao texto acadêmico, foco principal da produção textual no ensino superior. 


\section{REFERÊNCIAS}

BARTON, D. Talking about literacy. In: Literacy: an introduction to the ecology of written language. Cambridge, USA: Brackwell, 1994a. p. 10-30.

. The social bases of literacy. In: . Literacy: an introduction to the ecology of written language. Cambridge, USA: Brackwell, 1994b. p. 33-51.

FREIRE, Paulo. A importância do ato de ler: em três artigos que se completam. 23. ed. São Paulo: Cortez, 1989.

GONÇALVES, A. V. Gêneros textuais e reescrita: uma proposta de intervenção para o ensino de língua materna. Linguagem em (Dis)curso, Tubarão, v.10, n.1, jan./abr. 2010. Disponível em: < http://www.scielo. br/scielo.php?script=sci arttext\&pid=S151876322010000100002\&lng=en\&nrm=iso >. Accesso em: 5 fev. 2013.

KLEIMAN, A. B. (Org.). Os significados de letramento: uma nova perspectiva sobre a prática social da escrita. Campinas, São Paulo: Mercado de Letras, 1995.

KOCH, I. V.; ELIAS, V. M. Escrita e interação. In: tual. São Paulo: Contexto, 2009. p.31-52. . Ler e escrever: estratégias de produção tex-

RENEX. Política Nacional de Extensão Universitária. 2012. Disponível em: <http://www.renex.org.br/ documentos/2012-07-13-Politica-Nacional-de-Extensao.pdf> . Acesso em 20 nov. 2012.

SOUZA, A. L. L. A história da extensão universitária. Campinas: Alínea, 2000.

STREET, B. V. Literacy in theory and practice. Cambridge: Cambridge University Press, 1984.

Abordagens alternativas ao letramento e desenvolvimento. 2003. Disponível em: $<$ http://telecongresso.sesi. org.br/templates/header/index.php?language $=$ pt\&modo=bibliotec a\&act $=$ categoria\&cdcategoria $=22>$. Acesso em: 10 nov. 2009.

TINOCO, G. A. Mundos de letramento de professores em formação no agreste rio-grandense. In: OLIVEIRA, M. do S.; KLEIMAN, A. Letramentos múltiplos. Natal: UDUFRN, 2008. p. 63-92.

TREVISOL, J. V.; CORDEIRO, M. H.; HASS, M. Documento final da I Conferência de Ensino, Pesquisa e Extensão. In: (Org.). Construindo agendas e definindo rumos: I Conferência de Ensino, Pesquisa e Extensão da UFFS. Chapecó: UFFS, 2011. p. 23-70. 